\title{
MS22-P09 | Polymorphism AND the Role of F...F Interactions in Crystal PaCking OF FLUORINATED TOSYLATES
}

Korlyukov, Alexander (A.N.Nesmeyanov Institute of Organoelement Compounds of Russian Academy of Sciences, Moscow, RUS); Arkhipov, Dmitry (A.N.Nesmeyanov Institute of Organoelement Compounds of Russian Academy of Sciences, Moscow, RUS); Volodin, Alexander (INEOS, Moscow, RUS)

The peculiarities of interatomic interactions formed by fluorine atoms were studied in four tosylate derivatives $\mathrm{p}$ $\mathrm{CH}_{3} \mathrm{C}_{6} \mathrm{H}_{4} \mathrm{OSO}_{2} \mathrm{CH}_{2} \mathrm{CF}_{2} \mathrm{CF}_{3}$ and $\mathrm{p}-\mathrm{CH}_{3} \mathrm{C}_{6} \mathrm{H}_{4} \mathrm{OSO}_{2} \mathrm{CH}_{2}\left(\mathrm{CF}_{2}\right)_{n} \mathrm{CHF}_{2}$ ( $\mathrm{n}=1,5,7$ ) using $\mathrm{X}$-ray diffraction and quantum chemical calculations (Arkhipov et al., 2019). Compounds $\mathrm{p}-\mathrm{CH}_{3} \mathrm{C}_{6} \mathrm{H}_{4} \mathrm{OSO}_{2} \mathrm{CH}_{2}\left(\mathrm{CF}_{2}\right)_{n} \mathrm{CHF}_{2}(\mathrm{n}=1,5)$ were crystallized in several polymorph modifications. Analysis of intermolecular bonding was carried out using QTAIM approach, $\mathrm{NCl}$ method and energy partitioning scheme implemented in Crystal Explorer program (CE-B3LYP/6-31G(d,p)). All compounds are characterized by crystal packing of similar type and the contribution of intermolecular interactions formed by fluorine atoms to lattice energy is raised along with the increase of their amount. The energy of intraand intermolecular F...F interactions is varied in range $0.5-13.0 \mathrm{~kJ} / \mathrm{mol}$. Total contribution of F...F interactions to lattice energy does not exceed $40 \%$. Crystal structures of studied compounds are stabilized mainly by $\mathrm{C}-\mathrm{H}$...O and $\mathrm{C}-\mathrm{H}$...F weak hydrogen bonds. The analysis of intermolecular interactions and lattice energies in polymorphs of $\mathrm{p}-$ $\mathrm{CH}_{3} \mathrm{C}_{6} \mathrm{H}_{4} \mathrm{OSO}_{2} \mathrm{CH}_{2}\left(\mathrm{CF}_{2}\right)_{n} \mathrm{CHF}_{2}(\mathrm{n}=1,5)$ has shown that most stabilized ones are characterized by the least contribution of $\mathrm{F}$...F interactions.

The study was financially supported by Russian Science Foundation (grant 18-73-00339).

[1]Arkhipov, D. E., Lyubeshkin, A. V., Volodin, A. D. \& Korlyukov, A. A. (2019). Crystals. 9, 242. 